\title{
American Pediatric Society's 2014 John Howland Award acceptance lecture: saving lives through early diagnosis
}

Rebecca H. Buckley

This lecture was presented at the 2014 annual meeting of the Pediatric Academic Societies, Vancouver, British Columbia, Canada, on 4 May 2014.

$\mathbf{T}$ hanks to you, Alan, and to the Council membership for giving me the very distinguished John Howland Award. I am humbled and grateful for it and owe thanks to all of those who nominated me. Needless to say, I am especially honored to have been nominated by Dr Richard Stiehm, a distinguished scientist well known to all of you as the editor of the textbook "Immunologic Disorders in Infants and Children," which is now in its eighth edition, and also the editor of "Up to Date," which many of you use frequently. I am incredibly indebted to him for his untiring efforts on my behalf and for his memorable, albeit deeply embarrassing introduction and personal portrait of me, delivered with his usual great skill and well-placed humor. I also want to thank Ms Brenda Peat, APS executive secretary, for her extremely helpful assistance in the numerous planning events that led up to the annual meeting of the Pediatric Academic Societies.

In reviewing the list of former awardees, I see that I am just the third immunologist to receive the Howland Award, with Bob Good receiving it in 1987 and Dick Johnston in 2008. However, any accomplishments I have made should be attributed to the many people who have worked with me over the years and to the patients I have cared for. But they should also be credited to the great mentors I had in my early days in this field. When I was in medical school and in residency, where I was taught pediatrics on Duke's Howland Ward, I envisioned a career in general pediatrics. My father had been a general practitioner. However, one should never underestimate the power of a mentor. A prime example of this was Susan Dees, one of only two women in the department at the time, who was a very good teacher and role model (Figure 1). She convinced me that a career in Allergy and Immunology would be both interesting and enjoyable. However, after $2 \mathrm{y}$ of fellowship, I felt I needed more fundamental information about mechanisms underlying the diseases I was seeing. Fortuitously, Dr Bernard Amos, a codiscoverer of the HLA histocompatibility system, had just been recruited to Duke from Roswell Park to set up a Department of Immunogenetics. Fortunately, I was able to obtain a fellowship with one of his faculty, Dr Richard Metzgar, who taught me the fundamentals of laboratory research and launched my career in immunology (Figure 2). Once I returned to seeing patients and was struggling to climb the academic ladder, I had two more very important mentors, one being Dr James Sidbury, the Director of the Duke Clinical Research Unit and an expert in genetic diseases of metabolism (Figure 3). He gave me constant advice about how to advance my career, including taping over my lab bench one morning a cartoon showing a man hanging from the gallows with the caption below reading "didn't publish." Finally, I owe much to Dr Samuel Katz, who received the Howland Award in 2000 for his pioneering role in the development of the measles vaccine. He came to Duke from Harvard to Chair the Pediatric Department for $20 \mathrm{y}$ and was very supportive of my career advancement. I feel fortunate to have received outstanding mentorship from these individuals, in particular, and also from many others not mentioned.

Over the past few decades, I had the very great privilege of fully experiencing the excitement of the enormous information explosion in immunology and genetics. Both of these fields touch on every aspect of pediatrics, and whether or not you subspecialize in either, you still encounter aspects of them every day and will continue to do this throughout your careers. When I first came into this field, there was only one primary immunodeficiency disease known, Bruton's disease. Now, there are more than 200 diseases, and the molecular bases of $80 \%$ of them are known. Although I have enjoyed evaluating and caring for many types of very challenging immunodeficient patients over the years, I chose only one condition to discuss, because it is the classic example of how early diagnosis can save lives. With new technology, screening at birth should be possible in the future for many other genetic and immunologic diseases that we as Pediatricians see but are not screened for now, and it should eventually be possible to do this at point of service in the delivery room rather than having to wait $3 \mathrm{wk}$ for a piece of filter paper to be tested at a remote site.

The condition I chose to discuss is severe combined immunodeficiency (SCID), which is a fatal condition if not diagnosed and treated with hematopoietic stem cells soon after birth. While this was originally thought to be one condition, it is actually a syndrome of several molecular defects 


\section{Special Article}

\section{Buckley}

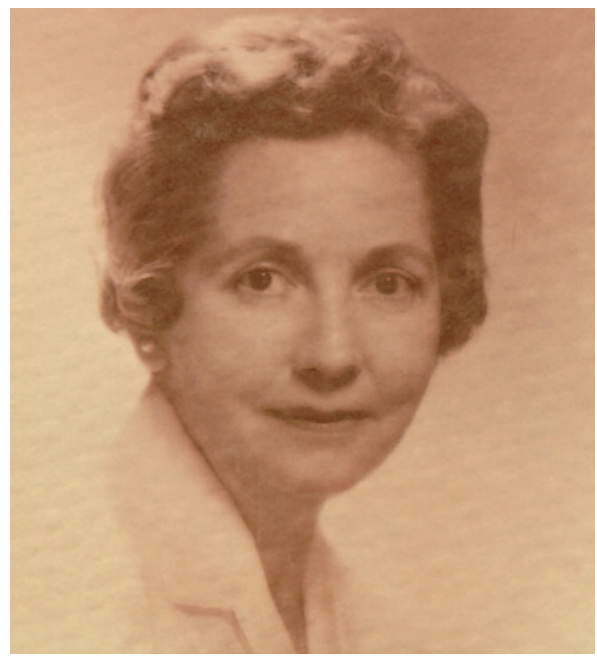

Figure 1. Photograph of Dr Susan Dees. Copyright by Duke University Medical Center Archives. Reprinted with permission.

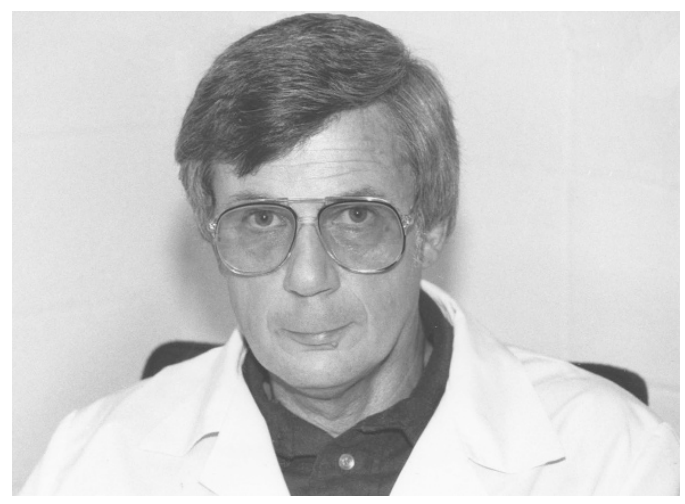

Figure 2. Photograph of Dr Richard Metzgar. Copyright by Duke University Medical Center Archives. Reprinted with permission.

characterized by the absence of $\mathrm{T}$ cells. There are at least 13 genes that, when mutated, cause this syndrome: 3 are cytokine receptor genes, 8 are antigen receptor genes, and the other 2 are CD45 deficiency and adenosine deaminase deficiency. People who are considering candidate conditions for newborn screening always want to know the incidence and whether there is an appropriate screening test. While it had been estimated that the incidence was $1: 100,000$, I had always thought SCID was much more common than generally thought, because many babies likely died before a diagnosis was made, and the death certificate said pneumonia, sepsis or meningitis, etc. In addition to infections, another big threat is live vaccines. The Academy of Pediatrics has recommended that every baby in the United States receive a rotavirus vaccination by 2 mo of age. Since SCID babies do not usually have any outward sign of abnormality at that age, the primary care physician has no way of knowing if an infant has SCID unless a complete blood count is done to show lymphopenia. Fortunately, in 2010, the Health and Human Services Secretary's Advisory Committee on Heritable Disorders of Newborns and Children unanimously approved adding SCID to the conditions routinely screened for at birth, and the Secretary approved this in May

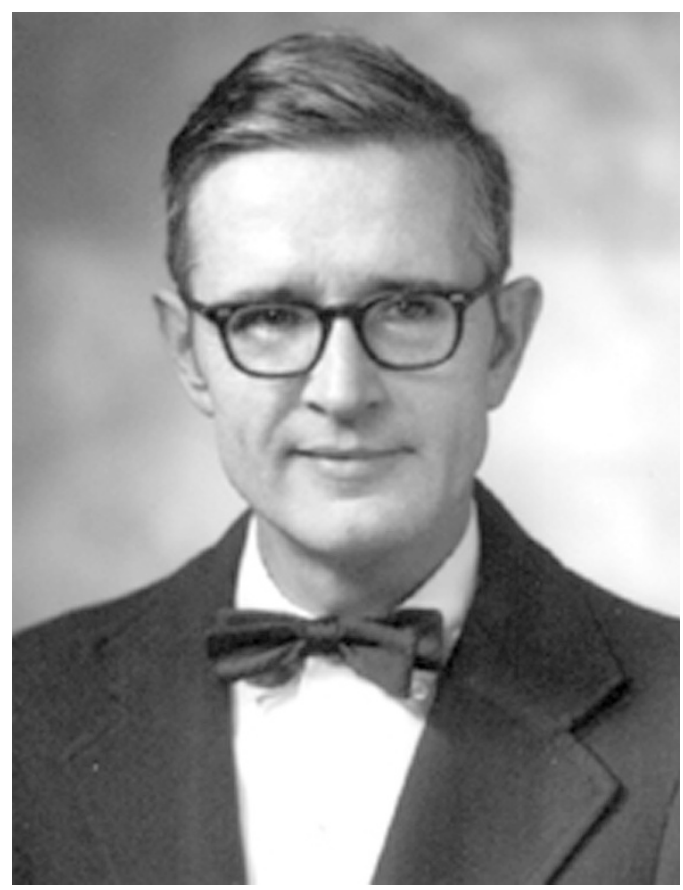

Figure 3. Photograph of Dr James Sidbury. Copyright by Duke University Medical Center Archives. Reprinted with permission.

of 2010 (1). There are now 21 states screening, and all have found SCIDs.

Regardless of the molecular type of SCID, T cells are lacking in all and that fact is the reason a single test can screen for all genetic types. Also, regardless of the molecular type of SCID, one treatment is effective for all, hematopoietic stem cell transplantation. Until 32 y ago, this could not be done unless there was a perfectly matched sibling. We now know that it is possible to use a haploidentical (half-matched) parent if one rigorously depletes all postthymic $\mathrm{T}$ cells from the donor cell suspension. This was first demonstrated by Müller-Ruchholtz et al. (2) in rats in Germany and by Reisner et al. (3) in Israel in mice. It is not often that one has the opportunity to directly apply to the treatment of patients the concepts and procedures developed from research studies in experimental animals that predicted this possibility. I have had the privilege and enjoyment of doing this now for over $30 \mathrm{y}$, after previously seeing infants with "bubble boy" disease invariably die in the first year of life because of lack of an effective treatment. Ninety percent of our patients did not have matched sibling donors, but we were able to use a mother or a father as a donor by rigorous T-cell depletion of their bone marrow. However, the most relevant information we learned from this 32-y experience is that, if one can transplant before 3.5 mo of life, there is a very high (92\%) survival rate.

The screening test that is used to detect SCID is based on testing by real-time PCR for pieces of DNA that are excised when the T-cell receptor genes undergo rearrangement in the thymus from their germline configuration. Only $\mathrm{T}$ cells that have recently left the thymus contain these DNA episomes, called T-cell receptor recombination excision circles, abbreviated as 
TRECs. Since SCIDs do not make T cells, they do not have any TRECs.

Because the infants who were transplanted in the first 3.5 mo of life did so well, we were interested in knowing whether infants who were transplanted early had evidence of earlier immune reconstitution. As we have previously published (4), they had higher T-cell counts earlier, higher naïve T-cell counts, and no difference in memory T-cell counts. T-cell function, as measured by lymphocyte responses to phytohemagglutinin, was also higher earlier in those transplanted early. Thymic output as measured by TRECs was also much higher earlier in those transplanted early. A chest computed tomography of a 4-y-old girl who received a stem cell transplant from her mother on day 18 of life revealed that she had a normal size thymus. We later showed that thymic output continues at least until 25 y posttransplantation (5). Finally, we have also summarized the long-term clinical features, showing the superior survival, a greater percentage with no problems, a lower need for a booster transplant, and fewer growth problems for those transplanted early (6). After day 105 of life, the attrition from infection begins and becomes more precipitous with increasing age; $75 \%$ of the deaths that occurred were from viral infections that the infants presented with. Of the different types of SCID we have transplanted in the first 3.5 mo of life, X-linked SCID is the most common, adenosine deaminase deficiency the next most common, and IL-7R $\alpha$ chain deficiency the third most common. One each of the deaths occurred in those three types and the fourth in a RAG2-deficient SCID. Of the 54 infants transplanted early, 37 were less than a month of age, and 12 of them were $10 \mathrm{~d}$ of age or younger. None were infected at the time of transplant. Except for the marrow cell infusions, the infants were outpatients. To avoid nosocomial hospital infections, they were discharged to an apartment and followed in the clinic every $1-2 \mathrm{wk}$ until T-cell function developed. They did not have central lines, and a majority were breastfed. As a result of being primarily an outpatient, the costs of treating these infants was much less than the cost of treating those who were diagnosed late and came in with severe infections.

There are differences in the frequencies of the various molecular types of SCID being identified by newborn screening as compared with frequencies in SCIDs diagnosed primarily after they had become ill. There are many more autosomal recessive conditions being detected, but this may vary, depending upon the different ethnicities or races in the different states. One of the benefits of a newborn screening test based on T-cell lymphopenia is that many conditions other than SCID are also being detected, including DiGeorge syndrome, trisomy 21, ataxia telangiectasia, and CHARGE syndrome. Many of the non-SCID conditions being detected would not be candidates for stem cell transplantation or, for that matter, any kind of transplantation unless there is neonatal leukemia or complete DiGeorge syndrome (less than $1 \%$ of DiGeorge patients) in which case a thymic transplant would be indicated. Those with idiopathic T-cell lymphopenia are very challenging and suggest that there are as yet unknown genes that, when mutated, cause T-cell defects that we do not know about as yet. These genes are waiting to be discovered in the future by the young people in this field.

I have a number of concerns for the future. I worry that many screen positive infants will receive unnecessary transplants. I am already aware that such has occurred. They need to be properly evaluated by an immunologist first. The second concern is "who will be transplanting these infants?" Because Medicaid offices are reluctant to refer patients out of state, I worry that they will be transplanted at a hospital with little or no experience in treating SCID. Finally, I worry that many will be given unnecessary pretransplant conditioning. All of our transplants were given without pretransplant chemotherapy or posttransplantation graft-vs.-host disease prophylactic agents. I know that most of you are familiar with the early adverse events from pretransplant chemotherapy, the most severe of which is veno-occlusive disease. However, in these very young infants, I also worry even more about the late effects on growth, tooth development, delayed puberty, and the fact that they will likely be sterile if they received pretransplant conditioning. In addition, there are already two publications recounting adverse effects on neurocognitive function $(7,8)$. To summarize, SCID is a pediatric emergency because early diagnosis is essential to an optimal outcome. Fortunately, newborn screening is going to help ensure that this will happen.

I hope you will appreciate that this example of how early diagnosis saves lives applies to many conditions in many pediatric subspecialties and even in general pediatrics. While most diseases are not fatal in infancy, early detection and prompt and ongoing treatment can ensure that growth and development and the quality of life are all improved and that secondary damage and catastrophes can be avoided.

I would like to end by thanking all of the young people who have trained at Duke and participated in research studies and in the care of these patients with rare genetic diseases. It has been my privilege to know all of you and to have participated in your education and careers. More than 100 fellows have trained at Duke and many, many more medical students and residents have also been involved with these patients. A special thanks is due to all of the patients and their families. As many others have said, it is the patients who are our greatest teachers!

Finally, and most importantly, I would like to thank the members of my family for allowing me to follow this path and for being in attendance today. My husband Ed who has supported me and given me valuable guidance over the past 59 years, my son Chuck who is here from Switzerland, my daughter Beth from London, who is here with her husband Erik, and my daughter Kathy Hatter, her husband Lou, and their children Julia and Charlie are all here at the meeting with me. I thank them all for coming and for all of their support over the years.

\section{REFERENCES}

1. Buckley RH. The long quest for neonatal screening for severe combined immunodeficiency. J Allergy Clin Immunol 2012;129:597-604; quiz 605-6.

2. Müller-Ruchholtz W, Wottge HU, Müller-Hermelink HK. Bone marrow transplantation in rats across strong histocompatibility barriers by 


\section{Special Article | Buckley}

selective elimination of lymphoid cells in donor marrow. Transplant Proc 1976;8:537-41.

3. Reisner Y, Itzicovitch L, Meshorer A, Sharon N. Hemopoietic stem cell transplantation using mouse bone marrow and spleen cells fractionated by lectins. Proc Natl Acad Sci USA 1978;75:2933-6.

4. Myers LA, Patel DD, Puck JM, Buckley RH. Hematopoietic stem cell transplantation for severe combined immunodeficiency in the neonatal period leads to superior thymic output and improved survival. Blood 2002;99:872-8.

5. Sarzotti-Kelsoe M, Win CM, Parrott RE, et al. Thymic output, T-cell diversity, and T-cell function in long-term human SCID chimeras. Blood 2009;114:1445-53.
6. Railey MD, Lokhnygina Y, Buckley RH. Long-term clinical outcome of patients with severe combined immunodeficiency who received related donor bone marrow transplants without pretransplant chemotherapy or post-transplant GVHD prophylaxis. J Pediatr 2009;155: 834-40.e1.

7. Titman P, Pink E, Skucek E, et al. Cognitive and behavioral abnormalities in children after hematopoietic stem cell transplantation for severe congenital immunodeficiencies. Blood 2008;112:3907-13.

8. Lin M, Epport K, Azen C, Parkman R, Kohn DB, Shah AJ. Long-term neurocognitive function of pediatric patients with severe combined immune deficiency (SCID): pre- and post-hematopoietic stem cell transplant (HSCT). J Clin Immunol 2009;29:231-7. 